\title{
Atrial fibrillation and heart failure with preserved ejection fraction
}

\author{
Agnieszka Komorowska, Małgorzata Lelonek \\ Department of Noninvasive Cardiology, Medical University of Lodz, Łódź, Poland
}

\section{Abstract}

Heart failure with preserved ejection fraction (HFpEF) and atrial fibrillation (AF) are the diseases that still challenges modern cardiology. Heart failure with preserved ejection fraction caused more than half of heart failure's cases and $\mathrm{AF}$ is one of the most common co-morbidities, that can worsen prognosis. The following article presents the current knowledge regarding HFpEF and the significance of AF in this group of patients.

Key words: heart failure with preserved ejection fraction, atrial fibrillation, HFpEF, AF

Folia Cardiologica 2021; 16, 4: 270-274

\section{Introduction}

It is currently estimated that heart failure with preserved ejection fraction (HFpEF) affects about $5 \%$ of the population over the age of 60 and accounts for more than half of diagnosed cases of heart failure (HF) [1]. As the population ages, this number will continue to increase in the coming years. Identification of a patient with HFpEF and establishing a correct diagnosis remains an important problem.

Atrial fibrillation (AF) is the most common type of arrhythmia. In Poland, prevalence is estimated at $600-$ -699 cases per 100000 people. Over the course of a lifetime, 1/3 of people will experience an AF episode. As with $\mathrm{HFpEF}$, the incidence of this disease increases with age [2].

Atrial fibrillation is associated with increased risk of death (1.5-3.5 times), ischemic stroke (it is responsible for $20-30 \%$ of strokes), left ventricular dysfunction (20-30\% of patients with AF), but also cognitive impairment/dementia (regardless of the history of stroke), depression, significantly reduced quality of life and a higher risk of hospitalization [2].

Taking into consideration confirmed risks associated with $A F$, particular emphasis is now placed on the identification of patients with asymptomatic AF. According to the European Society of Cardiology (ESC) guidelines, pulse screening is recommended for every person over 65 years of age and those at risk. New technologies, such as pressure monitoring devices equipped with arrhythmia detection algorithms and smartwatch recording bands are also currently in use, but an electrocardiogram (ECG) is required to confirm arrhythmia and establish a definitive diagnosis.

The advantages of screening for AF include the possibility of early detection of the disease, implementation of anticoagulation in people at risk of stroke (therefore, preventing the consequences of stroke), delaying/preventing adverse remodeling of the atrium, or reduction in the risk of hospitalization as a result of decompensation due to arrhythmia.

In view of the fact that AF is associated with multi-morbidity and the arrhythmia can run a different course depending on a patient, it has been proposed to set up patient care teams, which would include doctors of various specialties, nurses, as well as committed family members. The guidelines also highlight the patient's role in making decisions regarding the treatment of AF.

Patients with AF and heart failure represent a whole separate problem. First, the symptoms associated with arrhythmia may mirror those of HF, making it difficult to unequivocally establish the cause. An irregular heartbeat can make echocardiographic assessment difficult and usually requires a higher number of measurements and averaging of the results; moreover, different cut-off points are postulated for some variables. N-terminal pro-B-type natriuretic peptide (NT-pro BNP) concentrations are usually elevated in the presence of arrhythmia. Even though current ESC HF guidelines do not suggest different cut-off values for people with $A F$, this problem has been acknowledged. In clinical trials, either the number of participants with AF was limited 
or higher values of natriuretic peptides were applied e.g., in PARAGON-HF trial $>900 \mathrm{pg} / \mathrm{mL}$, for individuals with AF. The new HFA-PEFF algorithm [1] takes into account various cut-off values for natriuretic peptides depending on the rhythm (sinus rhythm vs. AF).

Processes taking place in the heart of a person with HFpEF involving the left atrium, i.e., enlargement, remodeling and progressive fibrosis, are known risk factors for the development of AF. Moreover, diseases coexisting with HFpEF [i.e. diabetes, hypertension, chronic kidney disease (CKD), chronic obstructive pulmonary disease (COPD)] are also recognized risk factors for $A F$.

It should be emphasized that atrial fibrillation is one of those diseases that can occur at any stage of HFpEF - i.e., it may precede the diagnosis of $\mathrm{HF}$, it can manifest itself at the time of diagnosis of HF (e.g., leading to acute heart failure as a result of cardiovascular decompensation by an arrhythmic episode), but it can also occur even many years after the diagnosis of HF. In view of numerous common risk factors, changes to the heart structure and coexistence of those two diseases, it is very difficult to assess the impact of one of them on the other.

Available literature data are inconsistent due to a number of factors. The proportion of people with AF in the studies varies significantly [higher in observational studies, usually lower in randomized controlled trials (RCTs)]. Studies targeting the HFpEF population are ongoing or are yet to be published, so most of the information we have available comes from previous randomized trials involving different HF subgroups.

Nowadays, we know that the pathophysiology of HFpEF differs from that of heart failure with reduced ejection fraction (HFrEF). Therefore, patients with HFpEF with statistically more comorbidities (as described above) were more likely to meet the criteria for exclusion from RCTs. On the other hand, in HFrEF atrial fibrillation is perceived as a result of disease progression, which may also result in the exclusion of such patients from RCTs. Therefore, AF groups are not representative of the size of their population. AF classification constitutes another problem. In some studies, only people with evidence of AF in an ECG on their first visit were included in the AF group. As a result, people with paroxysmal AF could be assigned to the control group.

Also, the criteria for the diagnosis of HFpEF in terms of left ventricular ejection fraction (LVEF) vary considerably depending on the study (LVEF $\geq 40 \%$ to $\geq 50 \%$ ).

Despite the complexity of the problem, we describe the significance of $A F$ in the population of patients with HFpEF based on selected publications.

\section{The significance of atrial fibrillation in HFpEF}

The analysis of the Framingham Heart Study [3] showed that for 'de novo' AF identified during follow-up, 37\% of the population were diagnosed with heart failure in the course of the study and among the cases of newly diagnosed heart failure, more than half (57\%) had AF.

Two studies from register analysis demonstrated a negative impact of AF on the course of HF. The Swedish Register [4] analyzed more than 40000 patients, 23\% of whom had HFpEF, 22\% - HFmrEF and 55\% HFrEF. The proportion of individuals with $\mathrm{AF}$ was the highest in the HFpEF group, at $65 \%$, followed by $60 \%$ in the HFmrEF group and $53 \%$ in the HFrEF cohort. In all types of HF, patients with AF were older, with a longer history of heart failure, were more likely to have a history of stroke, TIA, or heart attack. In the above-mentioned study, AF was associated with an increased risk of death, hospitalization for HF or stroke regardless of ejection fraction (including the group with normal LVEF). Similarly, Zafrir et al. [5] corroborated the trend that the highest percentage of AF is found in the HFpEF group (39\% of this population). AF was associated with older age but also reduced exercise tolerance and more pronounced HF symptoms. Among this group, AF was associated with a higher risk of achieving the composite endpoint (defined as death, cardiac event or hospitalization due to $\mathrm{HF}$ ) in the group of patients with preserved or mid-range ejection fraction - but not HFrEF.

Also, in the analysis of the CHARM clinical trial [6] AF was shown to be associated with a worse prognosis, especially in the group with preserved ejection fraction. In the CHARM study, the authors emphasized the significant contribution of AF to cardiac risk in the HFpEF group. Moreover, they pointed out that not only ongoing arrhythmia but also newly diagnosed AF constitutes an adverse prognostic factor. Similar conclusions were made in the TOPCAT study [7].

Lam et al. [8] analyzed the results of heart catheterization in 94 people with HFpEF (LVEF $\geq 45 \%$ ), 32 of whom had AF. They showed that AF was associated with lower peak $\mathrm{VO}_{2}$ values, higher NT-proBNP (NT-proBNP log) levels, and greater LAVI in echocardiographic examination compared to individuals with sinus rhythm. Also, the hemodynamic assessment showed higher mean pulmonary capillary wedge pressure (PCWP) despite similar E/e' values found in echocardiographic examination and a trend $(p=0.06)$ towards increased left ventricular end-diastolic pressures in this group.

In people with HFpEF, AF may be associated with an up to a 2 -fold increase in the risk of death [9]. Similarly, Cheng et al. [10] demonstrated that the presence of AF was associated with a worse prognosis in HFpEF patients. A number of studies $[5,6,8]$ pointed to symptomaticity of the disease - patients with AF usually present with a higher New York Heart Association (NYHA) class compared to those with sinus rhythm and similar ejection fraction.

Not only the mere presence of arrhythmia but also its type is relevant in the context of coexistence with HF. Newly diagnosed AF (de novo) is associated with a worse 
prognosis than already ongoing $\mathrm{AF}$ and this applies not only to the risk of stroke but also to total mortality or risk of hospitalization of cardiovascular causes $[6,7,11]$. Austrian researchers [12] demonstrated the negative impact of persistent/permanent AF on mortality and hospitalization on a group of more than 250 patients but failed to show such a relationship in the case of paroxysmal arrhythmia.

An analysis of the Get With The Guidelines - Heart Failure (GWTG-HF) registry [13] with regard to rhythm control versus rate control in patients with AF and HFpEF patients showed higher annual mortality in the rate control group (37.5\% vs. $30.8 \%, p<0.01)$. Importantly, the vast majority (13 825 people) were managed with rate control (vs. 1857 in the rhythm-control group.

Kotecha et al. [14] in his meta-analysis found that the risk of death from any cause over a 2-year follow-up period is the highest in the group of patients with AF and HFrEF; however, the risk of stroke and hospitalization due to exacerbation of HF is similar irrespective of ejection fraction. In contradiction to these findings, a study by Son et al. [15] showed that AF was associated with greater mortality (cardiovascular as well as all-cause) in the HFpEF group (but not HFmrEF or HFrEF) during the follow-up period (median duration of approx. 4 years).

\section{Treatment of AF}

A treatment scheme for patients with $\mathrm{AF}$, contained in an "ABC", was presented in 2020.

\section{'A' stands for anticoagulation - avoiding stroke}

The guidelines indicate new oral anticoagulants (NOAC) as the preferred anticoagulation therapy. Data from a meta-analysis of randomized clinical trials with new oral anticoagulants showed a $19 \%$ reduction in risk of significant strokes, more than $50 \%$ reduction in the risk of incidence of hemorrhagic stroke and a similar reduction in the risk of ischemic stroke compared to VKA [2].

The Loire Valley Atrial Fibrillation Project [16] did not demonstrate statistically significant differences with regard to the number of strokes/transient iachemic attacks (TIAs) or deaths depending on LVEF, although these numbers were increased in both HF groups. It is worth noting, however, that patients with $\mathrm{AF}$ and $\mathrm{HFpEF}$ received more points on the $\mathrm{CHADS}_{2}$ and $\mathrm{CHA}_{2} \mathrm{DS}_{2}$-VASc scales, which is not surprising given the higher number of diseases usually coexisting with HFpEF. Nevertheless, only 335/585 (61.4\%) people were anticoagulated.

The ESC guidelines also highlight the role of scales used for the assessment of bleeding risk to identify vulnerable patients, but even in such cases, it is recommended to initiate anticoagulation with more frequent control and elimination of possible modifiable risk factors for bleeding.

\section{'B' - better symptom control}

The ongoing discussion on the effectiveness and safety of rhythm control versus rate control strategies resulted in changes to the atrial fibrillation guidelines, where the roles of heart rhythm control and rate control strategies have been equated.

In people with mild symptoms or asymptomatic, rate control remains the best option. Additionally, this strategy is intended for people, in whom we have not been able to effectively restore the sinus rhythm or reduce the frequency of AF episodes, as well as, those in whom the risk of 'rhythm control' strategy outweighs the possible benefits of the therapy. Beta-blockers or non-dihydropyridine calcium channel blockers are the first-line agents for people with HFpEF and AF, followed by digoxin if these agents are not effective.

RACE trial did not show significant differences with regard to the NYHA class, the number of hospitalizations or clinical events between the subgroups of strict (HR $<80$ / /min) vs. lenient (HR $<110 / \mathrm{min})$ heart rate control. Thus, a control strategy aiming at $\mathrm{HR}<110 /$ min is acceptable if it does not cause symptoms [2].

In 2019, Sartipy [17] evaluated 9000 HFpEF patients, nearly $53 \%$ of whom had persistent atrial fibrillation. He confirmed that $A F$ is associated with a higher risk of death in the HFpEF population. Moreover, when analyzing mortality depending on heart rate, unlike in sinus rhythm, he did not notice a significant correlation, especially after 2 years of follow-up [for heart rate $>90 / \mathrm{min}$ the hazard ratio is $1.78(1.46-2.17)$; $1.08(0.80-1.46)$ and $0.73(0.46-1.17)$ for follow-up time of 0-2 years, 2-4 years and 4-6 years, respectively].

In the 2020 ESC guidelines, a rhythm control strategy is recommended to reduce the symptoms associated with AF and improve the quality of life (class IA). The rhythm control strategy is recommended especially in younger people with the first episode of AF, AF due to an 'acute condition', or short time from the diagnosis of AF, little atrial remodeling, and a small number of comorbidities.

In cases of paroxysmal AF or persistent AF with or without risk factors for AF recurrence (i.e., significant LA vol. enlargement, advanced patient age, long AF duration, CKD and other cardiovascular risk factors), pulmonary vein ablation is recommended if antiarrhythmic treatment is ineffective or not tolerated. In people with HFpEF and AF, amiodarone and dronedarone are the drugs of choice. The use of sotalol may also be considered but monitoring of QT and potassium levels, as well as, the elimination of other proarrhythmic factors are necessary (recommendation IIbA).

Maintaining sinus rhythm in people with HFpEF can be difficult, for example, due to old age, atrial remodeling and multiple comorbidities, which can make it more difficult to match suitable pharmacological treatment. However, a study from a Japanese center [18] showed that performing percutaneous $\mathrm{AF}$ ablation in people with $\mathrm{HFpEF}$ reduces 
Table 1. Review of selected studies involving patients with atrial fibrillation (AF) and heart failure with preserved ejection fraction (HFpEF)

\begin{tabular}{|c|c|c|c|c|c|}
\hline Name & $\begin{array}{l}\text { Framingham Heart } \\
\text { Study [3] }\end{array}$ & $\begin{array}{l}\text { Sartipy - Swedish } \\
\text { [17] }\end{array}$ & $\begin{array}{l}\text { CHARM (Candesartan in } \\
\text { Heart failure-Assessment } \\
\text { of Reduction in Mortality } \\
\text { and morbidity) [6] }\end{array}$ & McManus [11] & $\begin{array}{l}\text { TOPCAT - America } \\
\text { [7] }\end{array}$ \\
\hline $\begin{array}{l}\text { Type of } \\
\text { study }\end{array}$ & Observational & Observational & $\mathrm{RCT}$ & Observational & RCT \\
\hline $\begin{array}{l}\text { Inclusion } \\
\text { criteria }\end{array}$ & $\begin{array}{l}\text { Newly diagnosed AF } \\
\text { (group I) } \\
\text { Newly diagnosed HF } \\
\text { (including HFpEF if LVEF } \\
\geq 45 \% \text { ) (group II) }\end{array}$ & $\begin{array}{l}\text { Permanent AF (past } \\
\text { medical history of AF } \\
\text { + ECG evidence) } \\
\text { HFpEF (LVEF } \geq 50 \% \text { ) }\end{array}$ & $\begin{array}{l}\text { HFpEF (LVEF } \geq 40 \% \text { ) } \\
\text { AF in ECG on the first visit } \\
\text { Patients with a history } \\
\text { of AF but sinus rhythm } \\
\text { in ECG were assorted } \\
\text { to the non-AF group }\end{array}$ & HFpEF (LVEF $\geq 50 \%)$ & $\begin{array}{l}\text { HFpEF (LVEF } \geq 45 \% \text { ) } \\
3 \text { groups: no history of } \\
\text { AF, history of AF with- } \\
\text { out AF in ECG during } \\
\text { the visit, AF in ECG } \\
\text { during the visit }\end{array}$ \\
\hline $\begin{array}{l}\text { Population } \\
\text { size }\end{array}$ & $\begin{array}{l}1,737 \text { patients with a di- } \\
\text { agnosis of de novo AF } \\
1,166 \text { patients with a di- } \\
\text { agnosis of de novo HF } \\
{[479(41 \%)-\mathrm{HFpEF}]}\end{array}$ & $\begin{array}{l}9,090 \text { patients with } \\
\text { HFpEF }\end{array}$ & $\begin{array}{l}7,599 \text { patients with } \mathrm{HF} \text {, in- } \\
\text { cluding } 3,023 \text { with HFpEF }\end{array}$ & $\begin{array}{l}23,644 \text { patients with } \\
\text { HF, including } 60 \% \\
\text { with HF-PEF }(14,295)\end{array}$ & 1,765 patients \\
\hline $\begin{array}{l}\text { Mean fol- } \\
\text { low-up }\end{array}$ & $\begin{array}{l}\text { Approx. } 8 \text { years for } \mathrm{HF} \\
\text { events (7.5 } \pm 1.5 \text { years } \\
\text { and AF ( } 7.5 \pm 1.6 \text { years) }\end{array}$ & Approx. 2.9 years & 37.7 months & 1.8 years $(0.8-3.1)$ & Approx. 3.3 years \\
\hline $\begin{array}{l}\text { Number of } \\
\text { AF patients }\end{array}$ & $\begin{array}{l}\text { In a population with } \\
\text { newly diagnosed HF } \\
\text { (1,166 patients) } 32 \% \\
\text { were previously diag- } \\
\text { nosed with AF, 18\% were } \\
\text { diagnosed with AF within } \\
30 \text { days from the diag- } \\
\text { nosis, } 12 \% \text { developed } \\
\text { AF later }\end{array}$ & $4,794(52.7 \%)$ & $\begin{array}{l}670(17 \%) \text { in the HFrEF } \\
\text { group and } 478 \text { patients } \\
(19 \%) \text { in } \mathrm{HFpEF} \text { group at the } \\
\text { beginning of the study } \\
\text { In the course of the study, } \\
392 \text { patients developed } \\
\text { AF episodes, including } 5 \% \\
\text { from the HFpEF in the group } \\
\text { population (129 patients) }\end{array}$ & $\begin{array}{l}\text { Including } 9081 \\
(38.4 \%) \text { with the diag- } \\
\text { nosis of AF and } 2,348 \\
(9,9 \%) \text { with de novo } \\
\text { diagnosis } \\
\text { AF during follow-up } \\
\text { In the HFpEF group - } \\
\text { respectively, } 43,2 \% \\
\text { with the diagnosis of } \\
\text { AF and } 9.5 \% \text { with de } \\
\text { novo AF }\end{array}$ & $\begin{array}{l}760 \text { patients ( } 43 \%) \\
\text { with a past medical } \\
\text { history of AF (18\%) or } \\
\text { AF in ECG during the } \\
\text { visit ( } 25 \%) \\
\text { In } 6.3 \% \text { of patients } \\
\text { AF was identified } \\
\text { after randomization, } \\
\text { including } 85 \text { patients } \\
\text { with de novo AF ( } 8.5 \% \\
\text { of the population with- } \\
\text { out AF) }\end{array}$ \\
\hline Conclusions & $\begin{array}{l}\text { Group I: Among 1,737 } \\
\text { patients with newly diag- } \\
\text { nosed AF approx. } 37 \% \\
\text { had also HF. Among that } \\
\text { group - half had HFpEF } \\
\text { Group Il: among 1,166 } \\
\text { patients with de novo HF } \\
57 \% \text { had also AF. Diag- } \\
\text { nosis of AF was more } \\
\text { often associated with } \\
\text { the diagnosis of HFpEF } \\
\text { (32\% vs. } 23 \% \text { in case } \\
\text { of HFrEF) } \\
\text { Coexistence of AF and } \\
\text { HF was associated with } \\
\text { greater risk of death - } \\
\text { in the group with } \\
\text { de novo diagnosis } \\
\text { of HFpEF and AF } \\
\text { (HR 1.83, } 95 \% \text { Cl) }\end{array}$ & $\begin{array}{l}\text { During follow-up } \\
2,639 \text { patients from } \\
\text { the AF group died } \\
\text { (55\%). 1-year and } \\
5 \text {-year survival in } \\
\text { the group with sinus } \\
\text { rhythm vs. AF was, } \\
\text { respectively, } 84 \% \\
\text { vs. } 76 \% \text { and } 51 \% \\
\text { vs. } 38 \% \text { (log-rank } \\
\text { p }<0.001 \text { ) } \\
\text { Coexistence of AF } \\
\text { and HFpEF was } \\
\text { associated with } \\
\text { increased risk of } \\
\text { death (HR 1.21, } \\
p<0.001 \text { ) }\end{array}$ & $\begin{array}{l}\text { AF was associated with 1.7- } \\
\text {-fold increase in the risk of } \\
\text { death from cardiovascular } \\
\text { causes or risk of hospitali- } \\
\text { zation due to HF in patients } \\
\text { with HFpEF } \\
\text { In the group of patients with } \\
\text { HFpEF during follow-up 34\% } \\
\text { had an event of HF exacer- } \\
\text { bation vs. } 21 \% \text { in patients } \\
\text { with sinus rhythm } \\
\text { Multivariate analysis } \\
\text { showed that AF was an } \\
\text { independent risk factor for } \\
\text { cardiovascular death or } \\
\text { hospitalization among pa- } \\
\text { tients with HFpEF } \\
\text { (HR 1.32, 95\% Cl 1.06- } \\
-1.65, p=0.015 \text { ) but not } \\
\text { with HFrEF (HR 1.12, 95\% } \\
\text { Cl 0.97-1.29, p = 0.12) } \\
\text { Patients with de novo diag- } \\
\text { nosis of AF had higher risk } \\
\text { of morbidity and mortality } \\
\text { irrespective of ejection } \\
\text { fraction }\end{array}$ & $\begin{array}{l}\text { History of AF in pa- } \\
\text { tients with HFpEF } \\
\text { was associated with } \\
\text { increased risk of } \\
\text { all-cause death, hos- } \\
\text { pitalization due to HF } \\
\text { or any other cause, as } \\
\text { well as stroke } \\
\text { (HR } 1.11 ; 1.26 ; 1.16 \text {; } \\
1.91 ., \text { respectively) } \\
\text { De novo diagnosis of } \\
\text { AF was associated } \\
\text { with increased risk of } \\
\text { all-cause death, hos- } \\
\text { pitalization due to HF } \\
\text { or any other cause as } \\
\text { well as stroke } \\
\text { (HR 1.62; } 1.96 ; 1.43 ; \\
2.72, \text { respectively) }\end{array}$ & $\begin{array}{l}\text { Patients with AF in } \\
\text { ECG had the highest } \\
\text { risk of achieving pri- } \\
\text { mary endpoint (death } \\
\text { due to cardiovascular } \\
\text { causes, cardiac ar- } \\
\text { rest, hospitalization } \\
\text { due to HF) or all-cause } \\
\text { death (HR 1.34, 95\% } \\
\mathrm{Cl}: 1.09-1.65 \text {, } \\
\mathrm{p}<0.006 \text { ) } \\
\text { In the group of } \\
\text { patients with AF } \\
\text { diagnosed after } \\
\text { randomization, there } \\
\text { was a 2.3-fold greater } \\
\text { risk of achieving the } \\
\text { endpoint } \\
\text { (HR 2.32, 95\% } \\
\mathrm{Cl}: 1.59-3.40 \text {, } \\
\mathrm{p}<0.0001 \text { ). The risk } \\
\text { was highest during } \\
\text { the first } 90 \text { days from } \\
\text { the episode of AF }\end{array}$ \\
\hline
\end{tabular}

CHARM - Candesartan in Heart failure-Assessment of Reduction in Mortality and morbidity; RCT - randomized controlled trials; HF - heart failure; LVEF - left ventricular ejection fraction; ECG - electrocardiogram; HFrEF - heart failure with reduced ejection fraction; HR - hazard ratio; $\mathrm{Cl}$ - confidence interval 
the number of repeat hospitalizations due to exacerbation of HF ( $9 \%$ in the ablation group vs. $48 \%$ in the anti-arrhythmic therapy group, $\log p=0.0039$ ).

\section{'C' - cardiovascular risk factors}

\section{and treatment of comorbidities}

Treatment of concomitant diseases and cardiovascular risk factors affects the frequency of AF episodes both during pharmacotherapy as well as after effective ablation.

It is recommended that agents from specific groups [angiotensin-converting enzyme inhibitors (ACEI)/angiotensin receptor blockers (ARB), mineralocorticoid-receptor antagonists (MRA), statins] should be used if clinically indicated.

\section{Summary}

As described in the above article, atrial fibrillation and heart failure with preserved ejection fraction are common diseases, closely related i.a. due to the presence of mutual risk factors and etiology. However, their interrelationship requires further studies on patient groups representative of the population.

\section{Conflict of interest}

The authors do not declare a conflict of interest.

\section{References}

1. Pieske B, Tschöpe C, de Boer RA, et al. How to diagnose heart failure with preserved ejection fraction: the HFA-PEFF diagnostic algorithm: a consensus recommendation from the Heart Failure Association (HFA) of the European Society of Cardiology (ESC). Eur J Heart Fail. 2020; 22(3): 391-412, doi: 10.1002/ejhf.1741, indexed in Pubmed: 32133741.

2. Hindricks G, Potpara T, Dagres N, et al. ESC Scientific Document Group. 2020 ESC Guidelines for the diagnosis and management of atrial fibrillation developed in collaboration with the European Association for Cardio-Thoracic Surgery (EACTS). Eur Heart J. 2021; 42(5): 373-498, doi: 10.1093/eurheartj/ehaa612, indexed in Pubmed: 32860505.

3. Santhanakrishnan R, Wang Na, Larson MG, et al. Atrial fibrillation begets heart failure and vice versa: temporal associations and differences in preserved versus reduced ejection fraction. Circulation. 2016; 133(5): 484-492, doi: 10.1161/CIRCULATIONAHA.115.018614, indexed in Pubmed: 26746177.

4. Sartipy U, Dahlström U, Fu M, et al. Atrial fibrillation in heart failure with preserved, mid-range, and reduced ejection fraction. JACC Heart Fail. 2017; 5(8): 565-574, doi: 10.1016/j.jchf.2017.05.001, indexed in Pubmed: 28711451.

5. Zafrir B, Lund LH, Laroche C, et al. ESC-HFA HF Long-Term Registry Investigators. Prognostic implications of atrial fibrillation in heart failure with reduced, mid-range, and preserved ejection fraction: a report from 14964 patients in the European Society of Cardiology Heart Failure Long-Term Registry. Eur Heart J. 2018; 39(48): 4277-4284, doi: 10.1093/eurhearti/ehy626, indexed in Pubmed: 30325423.

6. Olsson LG, Swedberg K, Ducharme A, et al. CHARM Investigators. Atrial fibrillation and risk of clinical events in chronic heart failure with and without left ventricular systolic dysfunction: results from the Candesartan in Heart failure-Assessment of Reduction in Mortality and morbidity (CHARM) program. J Am Coll Cardiol. 2006; 47(10): 1997-2004, doi: 10.1016/j.jacc.2006.01.060, indexed in Pubmed: 16697316.

7. Pfeffer MA, Claggett B, Assmann SF, et al. Regional variation in patients and outcomes in the Treatment of Preserved Cardiac Function Heart Failure with an Aldosterone Antagonist (TOPCAT) trial. Circulation. 2015; 131(1): 34-42, doi: 10.1161/CIRCULATIONAHA.114.013255, indexed in Pubmed: 25406305.

8. Lam CSP, Rienstra M, Tay WT, et al. Atrial fibrillation in heart failure with preserved ejection fraction: association with exercise capacity, left ventricular filling pressures, natriuretic peptides, and left atrial volume. JACC Heart Fail. 2017; 5(2): 92-98, doi: 10.1016/j. jchf.2016.10.005, indexed in Pubmed: 28017355.

9. Mamas MA, Caldwell JC, Chacko S, et al. A meta-analysis of the prognostic significance of atrial fibrillation in chronic heart failure. Eur J Heart Fail. 2009; 11(7): 676-683, doi: 10.1093/eurjhf/hfp085, indexed in Pubmed: 19553398.

10. Cheng M, Lu X, Huang J, et al. The prognostic significance of atrial fibrillation in heart failure with a preserved and reduced left ventricular function: insights from a meta-analysis. Eur J Heart Fail. 2014; 16(12): 1317-1322, doi: 10.1002/ejhf.187, indexed in Pubmed: 25371247.

11. McManus DD, Hsu G, Sung SH, et al. Cardiovascular Research Network PRESERVE Study. Atrial fibrillation and outcomes in heart failure with preserved versus reduced left ventricular ejection fraction. J Am Heart Assoc. 2013; 2(1): e005694, doi: 10.1161/JAHA.112.005694, indexed in Pubmed: 23525446.

12. Schönbauer R, Duca F, Kammerlander AA, et al. Persistent atrial fibrillation in heart failure with preserved ejection fraction: Prognostic relevance and association with clinical, imaging and invasive haemodynamic parameters. Eur J Clin Invest. 2020; 50(2): e13184, doi: 10.1111/eci.13184, indexed in Pubmed: 31732964.

13. Kelly JP, DeVore AD, Wu J, et al. Rhythm control versus rate control in patients with atrial fibrillation and heart failure with preserved ejection fraction: insights from get with the guidelines-heart failure. J Am Heart Assoc. 2019; 8(24): e011560, doi: 10.1161/JAHA.118.011560, indexed in Pubmed: 31818219.

14. Kotecha D, Chudasama R, Lane DA, et al. Atrial fibrillation and heart failure due to reduced versus preserved ejection fraction: A systematic review and meta-analysis of death and adverse outcomes. Int J Cardiol. 2016; 203: 660-666, doi: 10.1016/j.ijcard.2015.10.220, indexed in Pubmed: 26580351.

15. Son MiK, Park JJ, Lim NK, et al. Impact of atrial fibrillation in patients with heart failure and reduced, mid-range or preserved ejection fraction. Heart. 2020; 106(15): 1160-1168, doi: 10.1136/heartjnl-2019-316219, indexed in Pubmed: 32341140.

16. Banerjee A, Taillandier S, Olesen JB, et al. Ejection fraction and outcomes in patients with atrial fibrillation and heart failure: the Loire Valley Atrial Fibrillation Project. Eur J Heart Fail. 2012; 14(3): 295-301, doi: 10.1093/eurjhf/hfs005, indexed in Pubmed: 22294759.

17. Sartipy U, Savarese G, Dahlström U, et al. Association of heart rate with mortality in sinus rhythm and atrial fibrillation in heart failure with preserved ejection fraction. Eur J Heart Fail. 2019; 21(4): 471-479, doi: 10.1002/ejhf.1389, indexed in Pubmed: 30698317.

18. Fukui A, Tanino T, Yamaguchi T, et al. Catheter ablation of atrial fibrillation reduces heart failure rehospitalization in patients with heart failure with preserved ejection fraction. J Cardiovasc Electrophysiol. 2020; 31(3): 682-688, doi: 10.1111/jce.14369, indexed in Pubmed: 31985099. 